\title{
Recurrence Rate of Primary Superficial Bladder Tumors (Uroepithelial Tumors) at 2-Year Follow-up and Its Relationship with Smoking
}

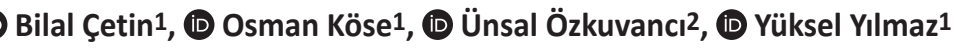 \\ 1izmir Katip Çelebi University, Atatürk Training and Research Hospital, Department of Urology, Izmir, Turkey \\ 2istanbul University Istanbul Faculty of Medicine, Department of Urology, Istanbul, Turkey
}

\section{Abstract}

Objective: In this study, we investigated recurrence rates of primary superficial bladder tumors (uroepithelial tumors) at 2-year follow-up and its relationship with smoking.

Methods: We retrospectively reviewed the data of 542 patients who underwent transurethral resection of bladder tumor for primary bladder tumor between 2006 and 2011 in our clinic. Our study included 105 patients with superficial bladder tumors, who had 2-year follow-up and $\leq 3 \mathrm{~cm}$ tumors in up to 3 foci. Data regarding age, gender, smoking, tumor stage, tumor grade, tumor size, number of tumors, postoperative early chemotherapy, induction bacillus Calmette-Guérin (BCG), adjuvant chemotherapy, recurrence within 2 years and time to recurrence were analyzed. Exposure to cigarette smoking was grouped as $\geq 20,30,40$ pack years.

Results: Recurrence was detected in 23 patients (21.9\%). There were 94 (89.5\%) smokers and 11 (10.5\%) non-smokers. In multivariate analysis using logistic regression, T category, 6 -week intravesical BCG, $<60$ years of age and $\geq 20$ pack year cigarette exposure were found to be effective parameters on recurrence $(p=0.022, p=0.042, p=0.011, p=0.042$, respectively).

Conclusion: Multivariate analysis of our study revealed that $\geq 20$ pack years of smoking shortened recurrence-free survival. Evaluation of long-term results of existing therapies and development of new treatment modalities are needed to better identify risk factors for recurrence of bladder tumors.

Keywords: Bladder cancer, smoking, recurrence

\section{INTRODUCTION}

According to the statistics, transitional cell carcinoma of the bladder is the second most common urological cancer after prostate cancer, and is an important cause of mortality and morbidity. In developed countries, it ranks $4^{\text {th }}$ in men and $9^{\text {th }}$ in women. Although there are many factors involved in the etiology of bladder cancer, the most important factor is smoking (1).

Most (90\%) of the bladder cancers are urothelial cancers (2). Approximately $80 \%$ of urothelial cancers of the bladder are limited to mucosa and submucosa at the time of diagnosis; therefore, they are named as "superficial bladder tumor" or "non-muscle-invasive bladder cancer" $(2,3)$. Although tumor can be controlled initially, it has the feature of frequent recurrence. In the first 3-month follow-up, recurrence rate ranges from $0 \%$ to $36 \%$ in single tumors and $7 \%$ to $75 \%$ in multiple tumors (4). Chen et al. (5) found that smoking was an independent risk factor for shorter recurrence-free survival in patients with T1 category, high-grade and multiple tumors who continued to smoke following bladder tumor diagnosis and primary treatment.

The aim of this study was to determine the relationship between the recurrence of primary superficial bladder tumors (uroepithelial tumors) with age, gender, tumorstage, tumorgrade, 
number of tumors, postoperative early chemotherapy, repeattransurethral resection of bladder tumor (re-TURBT), induction bacillus Calmette-Guérin (BCG), adjuvant chemotherapy and smoking.

\section{METHODS}

The data of 542 patients who underwent TURBT due to primary bladder tumor between 2006 and 2011 were evaluated retrospectively. Our study included 105 patients with superficial bladder tumors, who had 2-year follow-up and $\leq 3 \mathrm{~cm}$ tumors in up to 3 foci. Tumor size measurement was calculated based on the width of the TUR loop. Data regarding age, gender, smoking, tumor stage, tumor grade, tumor size, number of tumors, postoperative early chemotherapy, induction BCG, adjuvant chemotherapy, recurrence within 2 years and time to recurrence were analyzed. Exposure to cigarette smoking was grouped as $\geq 20,30,40$ pack years.

Following being informed about the disease and signing the informed consent form, the patients who were diagnosed as primary bladder tumor were operated. TURBT electroresection was performed by urology specialists. The operation was performed in the form of total resection, muscle sampling and fulguration of the tumor base.

Histopathological examinations of all patients were performed in the İzmir Atatürk Training and Research Hospital pathology laboratory. Tumors were staged according to the 2002 tumornode-metastasis system and were classified according to the World Health Organization, International Society of Urological Pathology 2004 tumor classification system. Cystoscopy and cytology follow-ups were performed quarterly in the first 2 years and every six months later after the diagnosis of superficial bladder tumor. Re-TURBT was performed in patients with recurrence.

\section{Statistical Analysis}

Normality of the data was assessed using one sample Kolmogorov-Smirnov test, histogram, Q-Q plot and box plot graphics. Data were given as mean, standard deviation, frequency and percentage. Nominal variables were evaluated by chi-squared test with Yates' continuity correction and Fisher's exact test. Logistic regression analysis was performed to determine the parameters that may be effective on recurrence. Factors affecting recurrence-free survival were evaluated by Cox regression analysis. Survival analysis was performed by KaplanMeier method. A two-tailed $p<0.05$ was accepted as statistically significant. Analysis was performed using SPSS 16.0 software program.

\section{RESULTS}

The mean age of the patients was $62.5( \pm 12.2)$ years. The number of smokers was 94 (89.5\%) and 11 (10.5\%) were nonsmokers. Eighty-nine (84.8\%) patients were male and 16 (15.2\%) were female. Of the 105 patients, 23 had recurrence (21.9\%). The pathological findings of 72 patients (68.6\%) were category Ta and 33 patients (31.4\%) were category T1. These tumors were low-grade in 72 patients (68.6\%) and high-grade in 33 patients (31.4\%). No simultaneous carcinoma-in-situ was reported in any of the patients. Single tumor was detected in 75 patients (71.4\%), while 30 patients (28.6\%) had tumors in 2 or 3 foci (Table 1 ).

Postoperative early intravesical chemotherapy was performed in 70 patients (66.7\%). The pathologies of the patients were evaluated, and 6-week intravesical chemotherapy (mitomycin-c, epirubicin) was performed in 14 patients (13.3\%) and 6-week intravesical BCG was performed in 25 patients (23.8\%). Re-TURBT was applied to 21 patients (20\%). Deep resection with perivesical fat tissue visualization occurred in a total of 3 patients (2.9\%), but no extravasation and additional complications were observed during postoperative follow-up. These patients did not receive postoperative early intravesical therapy. Only one patient had postoperative fever (1\%), and no patient had any bleeding complications requiring transfusion.

In the 2-year follow-up of the patients, five of 33 patients with category T1 tumors and 18 of 72 patients with category Ta tumors had recurrence $(p=0.38)$. Recurrence was observed in 15 of 72 patients with low-grade tumors and in eight of 33 patients with high-grade tumors $(p=0.89)$. Recurrence was found in seven of 21 patients who had re-TURBT and 16 of 84 patients who did not undergo re-TURBT $(p=0.24)$. Recurrence occurred in two of 11 non-smokers and 21 of 94 smokers $(p=0.99)$. The primary pathology of two non-smokers who had recurrence was Ta low-grade and recurrence pathology was Ta low-grade, and there was no progression. Recurrence was detected in 14 of 75 patients with single tumor, and recurrence was found in nine of 30 patients with tumors in 2 or 3 foci $(p=0.31)$. Recurrence was observed in 12 of 70 patients who underwent postoperative early intravesical chemotherapy and in 11 of 35 patients who did not $(p=0.16)$. Recurrence was observed in four of 14 patients who underwent postoperative 6-week intravesical chemotherapy and in 19 of 91 patients who did not $(p=0.73)$. Recurrence was observed in six of 25 patients who underwent postoperative 6-week intravesical BCG and in 17 of 80 patients who did not $(p=1)$. When the patients were grouped according to their gender, recurrence occurred in 21 of 89 male patients and 2 of 16 female patients ( $p=0.36$ ). When the patients were 
classified as over and under age 60, 15 of 47 patients under the age of 60 had recurrence and eight of 58 patients over 60 years of age had recurrence $(p=0.046)$. When the smoking status of the patients was divided into 20-30-40 pack/year above and below, the rate of recurrence was not statistically significant $(p=0.24$, $p=0.91, p=1$, respectively). The effects of patient characteristics, treatments and smoking (pack/year) on the recurrence were shown as separate tables (Tables 1, 2 and 3).

In multivariate analysis using logistic regression, pathologic T category, 6 -week intravesical BCG, $<60$ years of age and $\geq 20$ pack/year smoking parameters were found to be effective on recurrence in all patients $(p=0.022, p=0.042, p=0.011 p=0.042$, respectively) (Table 4).

In the survival analysis (Kaplan-Meier) in pathological T1 patients, $\geq 40$ packs/year smoking was found to be significant on recurrence-free survival $(p=0.033)$ (Figure 1).

When T1 patients were evaluated with Cox regression in multivariate analysis, re-TURBT and $\geq 40$ pack/year smoking were found to be significant in recurrence-free survival $(p=0.028$, $p=0.031$, respectively) (Table 5).

\begin{tabular}{|c|c|c|c|c|}
\hline & $\begin{array}{l}\text { Number of } \\
\text { patients }\end{array}$ & $\begin{array}{l}\text { Recurrence } \\
+\end{array}$ & $\begin{array}{l}\text { Recurrence } \\
\text { - }\end{array}$ & $\mathbf{p}$ \\
\hline \multicolumn{5}{|l|}{ Gender } \\
\hline Male & 89 & 21 & 68 & \multirow{2}{*}{$0.36^{*}$} \\
\hline Female & 16 & 2 & 14 & \\
\hline \multicolumn{5}{|l|}{ Age } \\
\hline $\begin{array}{l}<60 \text { years of } \\
\text { age }\end{array}$ & 47 & 15 & 32 & \multirow{2}{*}{$0.046^{* *}$} \\
\hline $\begin{array}{l}\geq 60 \text { years of } \\
\text { age }\end{array}$ & 58 & 8 & 50 & \\
\hline \multicolumn{5}{|l|}{ Smoking } \\
\hline Smoker & 94 & 21 & 73 & \multirow{2}{*}{$0.99 *$} \\
\hline Non-smoker & 11 & 2 & 9 & \\
\hline \multicolumn{5}{|c|}{ Pathological tumor stage } \\
\hline Ta & 72 & 18 & 54 & \multirow{2}{*}{$0.38 * *$} \\
\hline T1 & 33 & 5 & 28 & \\
\hline \multicolumn{5}{|l|}{ Grade } \\
\hline Low-grade & 72 & 15 & 57 & \multirow{2}{*}{$0.89 * *$} \\
\hline High-grade & 33 & 8 & 25 & \\
\hline \multicolumn{5}{|c|}{ Number of tumors } \\
\hline Single & 75 & 14 & 61 & \multirow{2}{*}{$0.31 * *$} \\
\hline 2 or 3 & 30 & 9 & 21 & \\
\hline
\end{tabular}

\begin{tabular}{|c|c|c|c|c|}
\hline & $\begin{array}{l}\text { Number } \\
\text { of } \\
\text { patients }\end{array}$ & $\begin{array}{l}\text { Recurrence } \\
+\end{array}$ & $\begin{array}{l}\text { Recurrence } \\
\text { - }\end{array}$ & $\mathbf{p}$ \\
\hline \multicolumn{5}{|c|}{ Re-TURBT } \\
\hline Yes & 21 & 7 & 14 & \multirow{2}{*}{$0.24^{* *}$} \\
\hline No & 84 & 16 & 68 & \\
\hline \multicolumn{5}{|c|}{ Postoperative early IVCT* } \\
\hline Yes & 70 & 12 & 58 & \multirow{2}{*}{$0.16^{* * *}$} \\
\hline No & 35 & 11 & 24 & \\
\hline \multicolumn{5}{|c|}{ 6-week IVCT* } \\
\hline Yes & 14 & 4 & 10 & \multirow{2}{*}{$0.73^{* *}$} \\
\hline No & 91 & 19 & 72 & \\
\hline \multicolumn{5}{|c|}{ Induction BCG } \\
\hline Yes & 25 & 6 & 19 & \multirow{2}{*}{$1 * * *$} \\
\hline No & 80 & 17 & 63 & \\
\hline
\end{tabular}

\begin{tabular}{|c|c|c|c|c|}
\hline & $\begin{array}{l}\text { Number } \\
\text { of } \\
\text { patients }\end{array}$ & $\begin{array}{l}\text { Recurrence } \\
+\end{array}$ & $\begin{array}{l}\text { Recurrence } \\
\text { - }\end{array}$ & $\mathrm{p}^{*}$ \\
\hline \multicolumn{5}{|c|}{ Pack year of smoking } \\
\hline$<20$ pack year & 31 & 4 & 27 & \multirow{2}{*}{0.24} \\
\hline$\geq 20$ pack year & 74 & 19 & 55 & \\
\hline \multicolumn{5}{|c|}{ Pack year of smoking } \\
\hline$<30$ pack year & 56 & 12 & 44 & \multirow{2}{*}{0.91} \\
\hline$\geq 30$ pack year & 49 & 11 & 38 & \\
\hline \multicolumn{5}{|c|}{ Pack year of smoking } \\
\hline$<40$ pack year & 80 & 18 & 62 & \multirow{2}{*}{1} \\
\hline$\geq 40$ pack year & 25 & 5 & 20 & \\
\hline
\end{tabular}

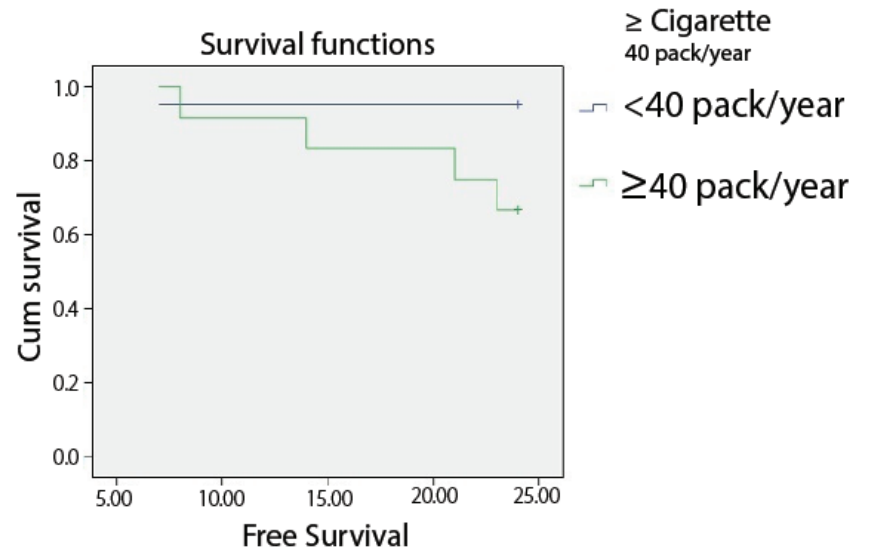

Figure 1. The effect of $>40$ pack/year smoking on recurrence-free survival in $\mathrm{T} 1$ tumors 
Regarding 72 patients with Ta pathology, recurrence was observed in eight of 48 patients who received postoperative early intravesical chemotherapy and in 10 of 24 patients who did not $(p=0.043)$. In the subgroup analysis, postoperative early intravesical chemotherapy in low-grade group patients was found to be statistically associated with low recurrence rates $(p=0.035)$.

\section{DISCUSSION}

In the treatment of superficial bladder tumors, the target is to keep recurrence and progression rates at the lowest levels. In a study by European Organisation for Research and Treatment of Cancer (EORTC) on 2596 patients with Ta and T1 tumors with a mean follow-up of 3.9 years (maximum 14.8 years) in 2006, recurrence was observed at least once in 1240 patients (47.8\%). The mean time to first recurrence was 2.7 years (6). In our study, 23 of 105 patients (21.9\%) had recurrence. In our study, the recurrence rate was lower since patient group included patients with $<3 \mathrm{~cm}$ tumor in up to 3 foci. The low number of tumors and smaller tumor size in our cohort represent low-risk group and the low recurrence rate can be explained in that way. In addition, evaluation of only the first 2 years and the majority of patients having Ta and low-grade bladder tumor were the other factors.

Smoking is the most important risk factor for bladder cancer and is thought to be responsible for approximately $50 \%$ of all patients $(7,8)$. Cigarette includes aromatic acid and polycyclic aromatic hydrocarbons excreted from the kidneys. In our study, 94 (89.5\%) of 105 patients were smokers. There was no statistically significant difference between the smokers and the non-smokers in terms of recurrence $(p=0.757)$. When the patients were divided into $\geq 20-30-40$ pack/year smokers, there was no statistical significance in terms of recurrence (Table 3). In multivariate analysis using logistic regression, patients with $\geq 20$ pack/year of smoking had more recurrence compared to patients with less smoking or no smoking $(p=0.042)$. Besides, multivariate analysis using Cox regression revealed that $\geq 20$ pack/year smoking decreased recurrence-free survival $(p=0.037)$. Although the carcinogen effect of cigarette has not been clearly defined, it is emphasized that there is adduction and mutagenicity effect of aromatic acid on DNA (9). In a study conducted by Flesner et al., (10) the multivariate analysis in patients who continued smoking revealed that recurrence-free survival was shorter compared to the patients who quitted and who were ex-smokers. The retrospective nature of our study, the limited characteristics of patients selected and the low number of patients were the main reasons for the lack of fully demonstrating the effect of smoking.

A possible outcome of this study was the extent to which smoking cessation and cessation time affected tumor recurrence. However, in our retrospective study, we determined that smoking cessation was not questioned in the follow-up of these patients, and we make great efforts to achieve smoking cessation in every patient diagnosed with and treated for bladder tumor. The fact

\begin{tabular}{|c|c|c|c|c|c|c|}
\hline & \multirow{2}{*}{ B } & \multirow{2}{*}{$\mathrm{SE}^{*}$} & \multirow{2}{*}{$\mathrm{p}$} & \multirow{2}{*}{ OR } & \multicolumn{2}{|c|}{$95 \% \mathrm{Cl}$ of $\mathrm{OR}^{* *}$} \\
\hline & & & & & Minimum & Maximum \\
\hline Re-TURBT & 1.17 & 0.68 & 0.085 & 3.226 & 0.850 & 12.243 \\
\hline PolvCT & -0.94 & 0.55 & 0.083 & 0.389 & 0.134 & 1.132 \\
\hline BCG 6 & 1.91 & 0.94 & $0.042 \#$ & 6.779 & 1.074 & 42.787 \\
\hline$<60$ years & -1.48 & 0.58 & $0.011 \#$ & 0.228 & 0.073 & 0.710 \\
\hline$\geq 20$ p-y smoking & 1.41 & 0.69 & 0.042\# & 4.080 & 1.052 & 15.820 \\
\hline pT & -2.32 & 1.01 & $0.022 \#$ & 0.098 & 0.014 & 0.713 \\
\hline
\end{tabular}

Table 5. The effective parameters on relapse-free survival in multivariate analysis using Cox regression in T1 patients

\begin{tabular}{|c|c|c|c|c|c|c|}
\hline & \multirow{2}{*}{ B } & \multirow{2}{*}{$S E^{*}$} & \multirow{2}{*}{$p$} & \multirow{2}{*}{$\mathrm{OR}$} & \multicolumn{2}{|c|}{$95 \% \mathrm{Cl}$ of $\mathrm{OR}^{* *}$} \\
\hline & & & & & Minimum & Maximum \\
\hline Re-TURBT & 2.63 & 1.19 & $0.028 \#$ & 13.928 & 1.330 & 145.822 \\
\hline
\end{tabular}


that $89.5 \%$ of the patients in our study consisted of smokers further emphasized the importance of this situation.

In studies on patient age and superficial bladder tumor characteristics, recurrence-free survival and prognosis were found to be better in young patients (11-13). In our study, recurrence occurred in 15 of 47 patients under 60 years of age and in eight of 58 patients aged 60 years and older $(p=0.026)$. In addition, recurrence-free survival under the age of 60 was found to be shorter than the patients aged 60 years and older $(p=0.029)$. Patients over 60 years of age had a higher rate of pathologic $\mathrm{T} 1$ and higher grade than those under 60 years $(\mathrm{p}=0.015$ and $p=0.044$, respectively). However, postoperative 6-week BCG application was found to be higher in patients older than 60 years ( $p=0.017)$. These conflicting results with the literature can be the result of many different factors affecting the recurrence of superficial bladder tumor.

In EORTC's 2006 risk score table for recurrence and progression in superficial bladder tumors, risk and progression scores were calculated using number of tumors, tumor size, prior recurrence rate, T category, carcinoma in situ (CIS), and grade (6). Following this, Club Urológico Español de Tratamiento Oncológico (CUETO) published progression and recurrence risk factors study in 2009 in which the results of 1,062 patients who underwent BCG were compared (14). Age, gender, previous recurrence status, number of tumors, T category, CIS, and tumor grade were used as risk factors. Using this table, the risk of recurrence was found to be lower in comparison with EORTC scoring system. Progression was lower in only high-risk patients. The low risk in CUETO tables can be correlated with BCG, which is an effective treatment. Many studies are needed for molecular markers to take place in the risk tables $(15,16)$.

In our study, multivariate analysis was performed using logistic regression in all patients and lower recurrence rates were found with pathological T1, 6-week intravesical BCG, $\geq 60$ years of age and $<20$ pack/year cigarette exposure $(p=0.022, p=0.042$, $p=0.011$ and $p=0.042$, respectively) (Table 4). A lower rate of recurrence in patients with $\mathrm{T} 1$ category than Ta category indicates the efficacy of adjuvant treatments. Considering the patient group included in this study, we cannot mention the validity of the same situation for general superficial bladder tumors. As a result of the meta-analyzes to be made in the coming years, it is predicted that the parameters affecting the recurrence will be defined more clearly.

In the subgroup analysis performed in our study, it was found that postoperative early intravesical chemotherapy in patients with low-grade group and Ta category was statistically significantly associated with low recurrence rates $(p=0.021, p=0.035$, respectively). With early instillation, the destruction of free tumor cells within the bladder after TUR had an ablation effect on residual tumors in the resection area and the tumors that were overlooked $(17,18)$. A single dose of early chemotherapy being an adequate adjuvant therapy in low-risk Ta tumors has been mentioned in the 2013 European guidelines (19). Postoperative early chemotherapy should be avoided in patients with suspected perforation or requiring irrigation. Serious drugrelated complications have been reported. These can be listed as peritonitis due to chemotherapeutic agent, infiltrative mass, and paralytic ileus causing colostomy and multiple organ failure (20). In our study, three patients did not undergo postoperative singledose chemotherapy because of suspicion of deep resection and perforation. Two of these patients had recurrence in the first 2 years.

\section{Study Limitations}

In our study, the direct significance of many factors with recurrence could not be demonstrated. The retrospective nature of our study and the inclusion of a narrow patient population were the limitations of our study. We think that more significant results can be obtained with prospective multicenter randomized studies.

\section{CONCLUSION}

Eighty-nine point five percent of the bladder cancer patients included in our study were found to be smoking. Multivariate analysis showed that $\geq 20$ pack/year of smoking decreased recurrence-free survival. Smoking cessation studies and providing public information are of great importance in the prevention of systemic diseases along with smoking-related bladder cancer and other cancers. It is understood that long-term (smoking cessation and have quitted it for a long time) studies are needed in order to understand how cessation of smoking and the duration of cessation affects recurrence in superficial bladder tumors. Evaluation of long-term results of current treatment modalities and development of new treatment modalities and histopathological genetic studies are needed in order to better identify risk factors affecting recurrence in bladder cancer.

\section{Ethics}

Ethics Committee Approval: Retrospective study.

Informed Consent: Retrospective study.

Peer-review: Externally peer-reviewed.

\section{Authorship Contributions}


Surgical and Medical Practices: B.Ç., O.K., Y.Y., Concept: B.Ç., Ü.Ö., O.K., Y.Y., Design: B.C.., Ü.Ö., Y.Y., Data Collection or Processing: B.Ç., Analysis or Interpretation: O.K., Literature Search: B.Ç., Writing: B.Ç., Ü.Ö., O.K., Y.Y.

Conflict of Interest: No conflict of interest was declared by the authors.

Financial Disclosure: The authors declared that this study received no financial support.

\section{REFERENCES}

1. Morrison AS, Ahlbom A, Verhoek WG, Aoki K, Leck I, Ohno Y, et al. Occupation and bladder cancer in Boston, USA, Manchester, UK, and Nagoya, Japan. J Epidemiol Community Health 1985;39:294-300.

2. Heney NM. Natural history of superficial bladder cancer. Prognostic features and long-term disease course. Urol Clin North Am 1992;19:429-33.

3. Rozanski TA, Grossman HB. Recent developments in the patholophysiology of bladder canser. AJR Am J Roentgenol 1994;163:789-92.

4. Kurth KH, Bouffioux C, Sylvester R, van der Meijden AP, Oosterlinch W, Brausi M. Treatment of superfisial bladder tumors: Achievements and needs. The EORTC Genitourinary Groups. Eur Urol 2000;37(suppl 3):1-9

5. Chen $\mathrm{CH}$, Shun $\mathrm{CT}$, Huang $\mathrm{KH}$, Huang $\mathrm{CY}$, Tsai YC, Yu HJ, et al. Stopping smoking might reduce tumour recurrence in nonmuscle-invasive bladder cancer. BJU Int 2007;100:281-6; discussion 286.

6. Sylvester RJ, van der Meijden AP, Oosterlinck W, Witjes JA, Bouffioux C, Denis $L$, et al: Predicting recurrence and progression in individual patients with stage Ta T1 bladder cancer using EORTC risk tables: a combined analysis of 2596 patients from seven EORTC trials. Eur Urol 2006;49:466-5; discussion 475-7.

7. Burger M, Catto JW, Dalbagni G, Grossman HB, Herr H, Karakiewicz P, et al. Epidemiology and risk factors of urothelial bladder cancer. Eur Urol 2013;63:234-41

8. Freedman ND, Silverman DT, Hollenbeck AR, Schatzkin A, Abnet CC Association between smoking and risk of bladder cancer among men and women. JAMA 2011;306:737-45.

9. Besaratinia A, Tommasi S. Genotoxicity of tobacco smoke-derived aromatic amines and bladder cancer: current state of knowledge and future research directions. FASEB | 2013;27:2090-100.
10. Fleshner N, Garland J, Moadel A, Herr H, Ostroff J, Trambert R, et al. Influence of smoking status on the disease-related outcomes of patients with tobaccoassociated superficial transitional cell carcinoma of the bladder. Cancer 1999;86:2337-45.

11. Shi B, Zhang K, Zhang J, Chen J, Zhang N, Xu Z. Relationship between patient age and superficial transitional cell carcinoma characteristics. Urology 2008;71:1186-90.

12. Aboutaieb R, Dakir M, Sarrf I, el Moussaoui A, Bennani S, el Mrini M, et al [Bladder tumors in young patients]. Prog Urol 1998;8:43-6.

13. Gassó Matoses M, Pelluch Auladell A, Megías Garrigós J, Romero Pérez P, Sánchez Marcos M, Mira Llinares A. [Bladder tumors in patients under $40 \mathrm{yr}$ of age. Our experience and review of the literature]. Arch Esp Urol 1991;44:257-8

14. Fernandez-Gomez J, Madero R, Solsona E, Unda M, Martinez-Piñeiro L, Gonzalez $\mathrm{M}$, et al. Predicting nonmuscle invasive bladder cancerrecurrence and progression in patients treated with bacillus Calmette-Guerin: the CUETO scoringmodel. J Urol 2009;182:2195-203.

15. van Rhijn BW, Zuiverloon TC, Vis AN, Radvanyi F, van Leenders GJ, Ooms BC, et al. Molecular grade (FGFR3/MIB-1) and EORTC risk scoresare predictive in primary non-muscle-invasive bladder cancer. Eur Urol 2010;58:433-41.

16. Alkhateeb SS, Neill M, Bar-Moshe S, Rhijn BV, Kakiashvili DM, Fleshner $\mathrm{N}$, et al. Long-term prognostic value of the combination of EORTC risk group calculator and molecular markers in non-muscle-invasive bladder cancer patients treatedwith intravesical Bacille Calmette-Guérin. Urol Ann 2011;3:119-26

17. Soloway MS, Masters S. Urothelial susceptibility to tumor cell implantation: influence of cauterization. Cancer 1980;46:1158-63.

18. Oosterlinck W, Kurth KH, Schröder F, Bultinck J, Hammond B, Sylvester R. A prospective European Organization for Research andTreatment of Cancer Genitourinary Group randomized trial comparing transurethral resection followed by a single intravesical instillation of epirubicin or water in single stage Ta, T1 papillary carcinoma ofthe bladder. J Urol 1993;14:749-52.

19. Babjuk M, Burger M, Zigeuner R, Shariat SF, van Rhijn BW, Compérat E, et al. EAU guidelines on non-muscle-invasive urothelial carcinoma of the bladder: update 2013. Eur Urol 2013;64:639-53.

20. Oddens JR, van der Meijden AP, Sylvester R. One immediate postoperative instillation ofchemotherapy in low risk Ta, $\mathrm{T} 1$ bladder cancer patients. Is it always safe? Eur Urol 2004;46:336-8. 